\title{
Dynamic Changes in Vesicular Glutamate Transporter 1 Function and Expression Related to Methamphetamine- Induced Glutamate Release
}

\author{
Karla A. Mark, ${ }^{1}$ Maria S. Quinton, ${ }^{1}$ Shelley J. Russek, ${ }^{2}$ and Bryan K. Yamamoto ${ }^{1}$ \\ Laboratories of ${ }^{1}$ Neurochemistry and ${ }^{2}$ Molecular Neurobiology, Department of Pharmacology and Experimental Therapeutics, Boston University School of \\ Medicine, Boston, Massachusetts 02118
}

The vesicular glutamate (GLU) transporter (VGLUT1) is a critical component of glutamatergic neurons that regulates GLU release. Despite the likely role of GLU release in drug abuse pathology, there is no information that links VGLUT1 with drugs of abuse. This study provides the first evidence that methamphetamine (METH) alters the dynamic regulation of striatal VGLUT1 function and expression through a polysynaptic pathway. METH increases cortical VGLUT1 mRNA, striatal VGLUT1 protein in subcellular fractions, and the $V_{\text {max }}$ of striatal vesicular GLU uptake. METH also increases glyceraldehyde-3-phosphate dehydrogenase (GAPDH) protein in the crude vesicle

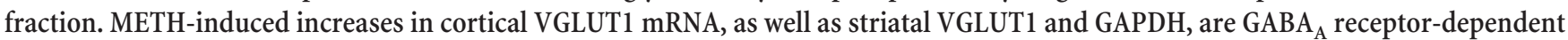
because they are blocked by $\mathrm{GABA}_{\mathrm{A}}$ receptor antagonism in the substantia nigra. These results show that VGLUT1 can be dynamically regulated via a polysynaptic pathway to facilitate vesicular accumulation of GLU for subsequent release after METH.

Key words: methamphetamine; VGLUT1; basal ganglia; striatum; substantia nigra; glutamate

\section{Introduction}

The regulation and dysregulation of glutamate (GLU) in the brain play important roles in normal and pathological processes, respectively (Lipton and Rosenberg, 1994; Price, 1999). Primary regulatory steps in glutamatergic neurotransmission involve the sequestration and storage of GLU in synaptic vesicles. The proteins responsible for GLU uptake by vesicles are the vesicular glutamate transporter (VGLUT) and the vesicle-associated glyceraldehyde-3-phosphate dehydrogenase (GAPDH)/3phosphoglycerate kinase complex that generates the ATP required for uptake by VGLUT (Ikemoto et al., 2003).

VGLUT1 and VGLUT2 are two vesicular GLU transporters that account for the majority of vesicular GLU uptake into glutamatergic neurons (Bellocchio et al., 2000; Takamori et al., 2000, 2001). VGLUT1 mRNA is primarily expressed in synaptic inputs to the striatum arising from cortical pyramidal neurons (Ni et al., 1995). In contrast, VGLUT2 is expressed predominantly in thalamostriatal neurons (Kaneko and Fujiyama, 2002). Furthermore, modulation of VGLUT expression is a mechanism by which glutamatergic neurons regulate GLU release. Targeted deletion of VGLUT1 reduces quantal size and glutamatergic neurotransmission (Wojcik et al., 2004). In contrast, overexpression of VGLUT1 increases the amount of GLU released per vesicle (Wil-

Received Jan. 3, 2007; revised April 18, 2007; accepted May 11, 2007.

This work was supported by National Institutes of Health Grant DA07606. The excellent technical advice on the RT-PCR experiments by Dr. Janine Steiger is greatly appreciated.

Correspondence should be addressed to Bryan K. Yamamoto, Department of Pharmacology, Boston University School of Medicine, 715 Albany Street, L-613, Boston, MA 02118. E-mail: bkyam@bu.edu.

D01:10.1523/JNEUROSCI.0013-07.2007

Copyright $\odot 2007$ Society for Neuroscience $\quad$ 0270-6474/07/276823-09\$15.00/0 son et al., 2005). Therefore, pharmacological agents that influence VGLUT expression could dramatically alter GLU release and GLU-dependent synaptic plasticity such as that involved in drug addiction (Lovinger et al., 2003). No studies to date have established a specific link between a psychoactive drug of abuse and VGLUT expression.

Methamphetamine (METH) is a widespread drug of abuse that causes a degeneration of dopamine (DA) terminals (Hotchkiss and Gibb, 1980; Ricaurte et al., 1982). METH-induced increases in extracellular concentrations of striatal DA and GLU (O'Dell et al., 1991; Stephans and Yamamoto, 1994) are known to contribute to the observed nerve terminal damage (Sonsalla et al., 1989; Nash and Yamamoto, 1992; Imam et al., 2001). Unlike METH-induced striatal DA release, which occurs directly via reverse transport, METH-induced striatal GLU release is indirect and initiated by the activation of the $\mathrm{D}_{1}$-associated striatonigral GABAergic pathway (Mark et al., 2004). More specifically, $\mathrm{METH}$-induced increases in the striatonigral GABA release act via nigral $\mathrm{GABA}_{\mathrm{A}}$ receptors that in turn decrease GABAergic nigrothalamic activity, disinhibit thalamocortical activity, and increase corticostriatal GLU release.

Extracellular concentrations of striatal GLU remain elevated for at least $4 \mathrm{~h}$ after METH (Stephans and Yamamoto, 1994). This finding is interesting because METH-induced DA release is no longer present during this time to stimulate $\mathrm{D}_{1} \mathrm{DA}$ receptors and sustain the activation of the polysynaptic pathway for enhanced corticostriatal GLU release. To address this caveat, we hypothesize that METH increases VGLUT1 synthesis and expression to enhance vesicular GLU uptake and sustain the observed increases in striatal GLU after METH. At present, there is no information on the regulation of VGLUT1 and whether drug-induced 
changes in VGLUT1 contribute to pathological states. These studies are the first to report evidence that a polysynaptic pathway dynamically regulates the expression and function of striatal VGLUT1, which in turn contributes to sustained corticostriatal glutamatergic neurotransmission that mediates METH-induced neurotoxicity.

\section{Materials and Methods \\ Subjects}

Male Sprague Dawley rats (Harlan Sprague Dawley, Indianapolis, IN) weighing 175-200 $\mathrm{g}$ at the beginning of experimental procedures were housed under a $12 \mathrm{~h}$ light/dark cycle (lights on from 7:00 A.M. to 7:00 P.M.) in a temperature $\left(21-23^{\circ} \mathrm{C}\right)$ and humidity-controlled room. The rats were initially housed four per cage until the day of surgery, after which they were individually housed. Food and water were available ad libitum. All experimental procedures were performed between 7:00 A.M. and 7:00 P.M. and performed in accordance with the National Institutes of Health Guide for the Care and Use of Laboratory Animals.

\section{Drugs}

1(S),9(R)-(-)-Bicuculline methobromide (BIC) was obtained from Sigma-Aldrich (St. Louis, MO). METH was supplied by the National Institute on Drug Abuse (Research Triangle Park, NC). Doses of METH refer to the weight of the salt. Four injections of METH $(10 \mathrm{mg} / \mathrm{kg})$ were administered intraperitoneally every $2 \mathrm{~h}$. BIC $(10 \mu \mathrm{M})$ was administered via reverse dialysis in modified Dulbecco's buffered saline (in mM): 137 $\mathrm{NaCl}, 2.7 \mathrm{KCl}, 0.5 \mathrm{MgCl}_{2}, 8.1 \mathrm{Na}_{2} \mathrm{HPO}_{4}, 1.5 \mathrm{KH}_{2} \mathrm{PO}_{4}, 1.2 \mathrm{CaCl}_{2}$, and 5 D-glucose, $\mathrm{pH}$ 7.4. This concentration of BIC was chosen because it was shown previously to completely block METH-induced increases in corticostriatal GLU release and the long-term depletions in DA tissue content $7 \mathrm{~d}$ later (Mark et al., 2004). The vehicle control medium for this perfusion was prepared identically but without the BIC.

\section{Experimental procedures}

For the microdialysis experiments, all rats were anesthetized with a combination of xylazine $(12 \mathrm{mg} / \mathrm{kg})$ and ketamine $(80 \mathrm{mg} / \mathrm{kg})$ and placed into a Kopf stereotaxic frame. The skull was exposed, and a hole was drilled through the skull above the substantia nigra $(\mathrm{SN})$ at a $15^{\circ}$ angle [anteroposterior (AP), -5.6; mediolateral (ML), \pm 4.1 ; dorsoventral (DV), $-10.2 \mathrm{~mm})]$ and the lateral striatum $[\mathrm{AP},+1.2 ; \mathrm{ML}, \pm 3.2 ; \mathrm{DV},-8.2$ $\mathrm{mm})$ ] (Paxinos and Watson, 1982). All dialysis probes were of a concentric flow design and constructed as described previously by Yamamoto and Pehek (1990). The lengths of the active dialysis membranes (Spectra/ Por; Spectrum Laboratories, Rancho Dominguez, CA) (molecular weight cutoff, 6000; outer diameter, $210 \mu \mathrm{M}$ ) were as follows: striatum, 4 $\mathrm{mm}$; substantia nigra, $1.5 \mathrm{~mm}$. The probes were then lowered to the appropriate position and secured to the skull with three stainless steel screws and cranioplastic cement.

\section{Microdialysis procedures}

The day after surgery, modified Dulbecco's PBS medium or BIC was pumped via a dual-channel swivel (Instech Laboratories, Plymouth Meeting, PA) through the microdialysis probes with a Harvard Model 22 syringe infusion pump (Harvard Apparatus, Holliston, MA) at a rate of 2 $\mu \mathrm{l} / \mathrm{min}$ as described previously (Matuszewich and Yamamoto, 1999). METH or saline injections were immediately administered after perfusion. For the extended microdialysis experiment, dialysate samples were collected during a baseline period and then for the last 20 min every $4 \mathrm{~h}$ up to $24 \mathrm{~h}$ after the fourth drug administration. Rectal temperatures were measured $1 \mathrm{~h}$ after each of four injections of either saline or METH.

\section{Preparation of striatal subcellular fractions}

Synaptosomal, membrane-bound, and crude vesicle fractions were prepared from whole striatal tissue via differential centrifugation as described previously (Kadota and Kadota, 1973; Teng et al., 1997, Riddle et al., 2002). Briefly, whole striata were dissected and homogenized in icecold $0.32 \mathrm{~m}$ sucrose ( $50 \mathrm{mg}$ of striatal wet weight/ $1 \mathrm{ml}$ of sucrose) and centrifuged $\left(800 \times g\right.$ for $\left.24 \mathrm{~min} ; 4^{\circ} \mathrm{C}\right)$ to remove nuclei and large debris. All of the supernatant in close proximity to the pellet was taken. The supernatant $(\mathrm{S} 1)$ was centrifuged at high speed $(22,000 \times g$ for $17 \mathrm{~min}$; $4^{\circ} \mathrm{C}$ ), and the pellet (P2) retained was the crude synaptosomal fraction. This fraction was resuspended in ice-cold distilled $\mathrm{H}_{2} \mathrm{O}(200 \mathrm{mg} / 1 \mathrm{ml})$ and centrifuged at high speed $\left(22,000 \times g\right.$ for $\left.17 \mathrm{~min} ; 4^{\circ} \mathrm{C}\right)$. The resulting supernatant (S3) was the crude vesicle fraction (non-membraneassociated fraction). The remaining pellet (P3) was resuspended (200 $\mathrm{mg} / 1 \mathrm{ml}$ ) in ice-cold distilled $\mathrm{H}_{2} \mathrm{O}$ to yield the membrane-bound fraction. Protein concentrations of each fraction were determined by the method of Bradford using bovine serum albumin as the standard.

\section{Western blot analysis for VGLUT1, VGLUT2, GAPDH, and synaptotagmin immunoreactivity}

Proteins from all fractions were then diluted with $2 \times$ Tris-glycine loading buffer (1:2 dilution; Invitrogen, Carlsbad, CA) and subject to SDSPAGE on 10\% Tris-glycine gel (for VGLUT1 and VGLUT2 immunoreactivity) in running buffer ( $25 \mathrm{~mm}$ Tris, $192 \mathrm{~mm}$ glycine, $0.2 \%$ SDS) for 75 min at $150 \mathrm{~V}$. For VGLUT1 immunoreactivity, the amounts of protein loaded per lane were as follows: synaptosomal, $5 \mu \mathrm{g}$; membrane-bound, $2.5 \mu \mathrm{g}$; crude vesicle, $2.5 \mu \mathrm{g}$. For VGLUT2 immunoreactivity, $5 \mu \mathrm{g}$ of protein was loaded per lane for all fractions. Samples were then electroblotted onto to a polyvinylidene difluoride membrane in transfer buffer (25 mu Tris, 192 mu glycine, 20\% methanol, 0.2\% SDS). After transfer, membranes were rinsed in TBS and incubated in 5\% blocking buffer ( 10 mм Tris, $150 \mathrm{~mm} \mathrm{NaCl}, 5 \%$ nonfat dry milk, and $0.05 \%$ Tween 20 ), $\mathrm{pH}$ 8.0, for $1 \mathrm{~h}$ to block nonspecific binding. Membranes were then incubated for $1 \mathrm{~h}$ at room temperature in primary antibody diluted in 5\% blocking buffer (rabbit anti-VGLUT1, 1:20,000; rabbit anti-VGLUT2, 1:3300; MAb Technologies, Stone Mountain, GA). Membranes were then rinsed twice and washed four times for $3 \mathrm{~min}$ in TBS and then incubated in secondary antibody (peroxidase-conjugated goat anti-rabbit; 1:2500 in 5\% blocking buffer; Millipore, Billerica, MA) for $1 \mathrm{~h}$ at room temperature. Membranes were then washed as described above and visualized via ECL detection reagents (RPN2106; GE Healthcare, Piscataway, NJ). Bands on the blots were quantified by densitometry using Kodak (Rochester, NY) 1D Image Analysis software. Membranes used to measure GAPDH and synaptotagmin immunoreactivity were then rinsed in TBS and stripped for $30 \mathrm{~min}$ in $1 \times$ mild stripping buffer (ReBlot Plus Mild Antibody Stripping Solution; Millipore) and blocked twice for $30 \mathrm{~min}$. Membranes were then incubated overnight at $4^{\circ} \mathrm{C}$ with goat anti-GAPDH primary antibody (1:1000; Santa Cruz Biotechnology, Santa Cruz, CA) and incubated in secondary antibody (peroxidaseconjugated rabbit anti-goat; 1:2500; Millipore) in blocking buffer for $1 \mathrm{~h}$ at room temperature. Membranes were rinsed and developed as described above. Synaptotagmin immunoreactivity was used as a loading control to assess the amount of vesicle protein loaded onto the gels. Membranes were incubated in blocking buffer for $30 \mathrm{~min}$ before overnight incubation with rabbit anti-synaptotagmin primary antibody (1: 2500; Millipore). Membranes were then rinsed and incubated with HRPconjugated goat anti-rabbit antibody (1:2500) before development. This approach normalizes differences in the development of the ECL reagent between the blots. Each blot contained all experimental groups and normalized to saline controls to ensure standardization across all blots.

\section{Real-time reverse transcription- $P C R$}

Total RNA was extracted from $400 \mu \mathrm{m}$ coronal rat parietal cortex slices on the side ipsilateral to the probe placements in the SNr using a RNeasy minikit (Qiagen, Valencia, CA). The parietal/somatosensory cortex was chosen because this particular region of the cortex has been shown to be affected by METH (Eisch et al., 1998). Real-time reverse transcription (RT)-PCR assays were performed using the ABI PRISM 7900HT instrument (Applied Biosystems, Foster City, CA). VGLUT1 primers and probes that target an exon/intron boundary in the rat VGLUT1 gene (GenBank accession number NM_053859) were designed using Primer Express version 1.5a software (Applied Biosystems). All Taqman probes were synthesized by Applied Biosystems, and forward and reverse primers were synthesized by Oligos Etc. (Wilsonville, OR). Cyclophilin was used as an endogenous control to normalize mRNA levels (Steiger et al., 2004). The forward and reverse primers for rat VGLUT1 were $5^{\prime}$ GGATTTATCTGCCAAAAATCGC-3' and 5'-CAACATATTTAGGGTGGAGGTAGC-3'. The forward and reverse primers for rat cyclophilin 
were 5' -TGCAGACATGGTCAACCCC-3' and 5' -CCCAAGGGCTCGCCA-3'. The Taqman probes were synthesized with the fluorescent reporter FAM (6-carboxy-fluorescein) attached to the $5^{\prime}$-end and the quencher dye TAMRA (6-hydroxy-tetramethyl-rhodamine) attached to the $3^{\prime}$-end. The sequence of the VGLUT1 probe was $5^{\prime}$ CAACAGGGTCTTTGGTTTGCCATTG-3'. The sequence of the cyclophilin probe was 5'-CCGTGTTCTTCGACATCACGGCTG-3'.

The standard curves for relative quantification were generated using 0-100 ng of total RNA isolated from rat whole brain. Total RNA (20 ng) from the rat cortex was tested. Reactions were performed in triplicate in a final volume of $50 \mu \mathrm{l}$ containing Taqman One Step RT-PCR master mixture (Applied Biosystems), $250 \mu \mathrm{m}$ VGLUT1 probe, $900 \mathrm{~nm}$ VGLUT1 primers, $200 \mathrm{~nm}$ cyclophilin primers, and $100 \mathrm{~nm}$ cyclophilin probes. Two aliquots of $20 \mu \mathrm{l} /$ reaction were loaded in a 384 -well plate. Thermocycling was done under the following conditions: $50^{\circ} \mathrm{C}$ for $30 \mathrm{~min}, 95^{\circ} \mathrm{C}$ for $10 \mathrm{~min}$, and $50 \mathrm{cycles}$ of $95^{\circ} \mathrm{C}$ for $15 \mathrm{~s}$ and $60^{\circ} \mathrm{C}$ for $1 \mathrm{~min}$. The relative amount of each VGLUT1 mRNA was normalized to the relative amount of cyclophilin (internal control).

\section{Microdialysis measures of glutamate uptake into isolated synaptic vesicles}

A novel application of the microdialysis technique was developed that offers the advantage of continuous in vitro monitoring over time of extravesicular changes in exogenously added GLU. Striatal subcellular fractions were prepared as described above. Isolation of synaptic vesicles was performed as described previously (Ikemoto et al., 2003) with a few modifications. Briefly, the remaining supernatant (S3) containing synaptic vesicles were subjected to 0.4 and $0.6 \mathrm{M}$ sucrose density gradient centrifugation $\left(65,000 \times g\right.$ for $\left.1 \mathrm{~h} ; 4^{\circ} \mathrm{C}\right)$. The synaptic vesicles were isolated from the upper part of $0.4 \mathrm{M}$ sucrose layer. Protein concentrations were determined by the method of Bradford using bovine serum albumin

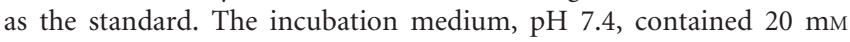
HEPES-KOH, $0.25 \mathrm{~m}$ sucrose, $4 \mathrm{~mm} \mathrm{MgSO}_{4}, 4 \mathrm{~mm} \mathrm{KCl}$, and $2 \mathrm{~mm}$ $\mathrm{L}$-aspartic acid ( $\mathrm{pH}$ adjusted to 7.4 by the addition of Tris-base). A microdialysis probe was lowered into the sample tube, and incubation medium was reverse dialyzed at a flow rate of $40 \mu \mathrm{l} / \mathrm{min}$. The probe was allowed to equilibrate for $40 \mathrm{~min}$ at $30^{\circ} \mathrm{C}$ before the addition of GLU. $\operatorname{GLU}(50,100,500,1000$, or $2000 \mu \mathrm{M})$ was then added to the incubation medium, and three baseline samples were collected every $30 \mathrm{~s}$. The concentrations of GLU used were based on previously published vesicular GLU uptake experiments (Fykse et al., 1992; Ikemoto et al., 2003). Synaptic vesicles $(5 \mu \mathrm{g})$ were added to the incubation medium and incubated with GLU for $10 \mathrm{~min}$ at $30^{\circ} \mathrm{C}$. GLU uptake was initiated by the addition of $2 \mathrm{~mm}$ ATP or equivalent amount of incubation medium (no ATP control), and samples were collected every $30 \mathrm{~s}$ for $1.5 \mathrm{~min}$ at $30^{\circ} \mathrm{C}$. This time course represented the most linear portion of the GLU uptake curve. GLU uptake was measured as the GLU concentration remaining in the incubation medium. For the vesicular GLU uptake experiments, doublereciprocal plots were used to calculate $K_{\mathrm{m}}$ and $V_{\max }$ values. In all of these experiments, GLU uptake was expressed as nanomoles per minute per milligram of protein.

\section{Biochemical measurements}

Glutamate. The concentrations of GLU from the vesicular uptake assay were determined by HPLC with electrochemical detection. GLU was derivatized with $o$-pthaldialdehyde (OPA) (Donzanti and Yamamoto, 1988). Briefly, the stock derivatization reagent was prepared by dissolving $27 \mathrm{mg}$ of OPA in $9 \mathrm{ml}$ of $0.1 \mathrm{M}$ sodium tetraborate, $\mathrm{pH} 9.4$, and $1 \mathrm{ml}$ of $100 \%$ methanol to which $10 \mu \mathrm{l}$ of $\beta$-mercaptoethanol was added. This stock solution was then diluted 1:3 with sodium tetraborate buffer. A 10 $\mu \mathrm{l}$ aliquot of this reagent solution was added to $20 \mu \mathrm{l}$ of dialysate or standard, vortexed, and allowed to react for $1.5 \mathrm{~min}$ before injecting onto a C18 column $(100 \times 2.0 \mathrm{~mm} ; 3 \mu \mathrm{m}$ particle size; Phenomenex, Torrance, CA). GLU was eluted using a mobile phase consisting of $0.1 \mathrm{M}$ sodium phosphate and $0.1 \mathrm{~mm}$ EDTA in $10 \%$ methanol at pH 6.7. GLU was detected with an LC-4C amperometric detector (Bioanalytical Systems, Lafayette, IN) using a $6 \mathrm{~mm}$ glassy working electrode maintained at a potential of $0.6 \mathrm{~V}$ relative to an $\mathrm{Ag} / \mathrm{AgCl}$ reference electrode.

Dopamine. Striatal extracellular concentrations of dopamine were

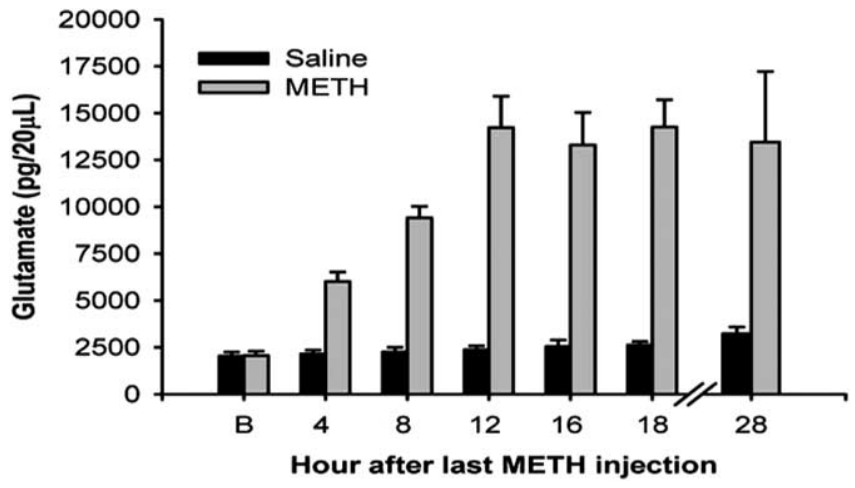

Figure 1. The effect of METH on extracellular concentrations of GLU in the lateral striatum. Four injections of METH $(10 \mathrm{mg} / \mathrm{kg})$ or saline $(1 \mathrm{ml} / \mathrm{kg})$ were given, one injection every $2 \mathrm{~h}$. Dialysate samples were collected in the striatum during a baseline period ( $\mathrm{B}$ ) and then during the last $20 \mathrm{~min}$ of every $4 \mathrm{~h}$ for up to $24 \mathrm{~h}$ after either METH or saline administration. Data are presented as mean \pm SEM. METH administration significantly increased extracellular GLU concentrations compared with saline-treated rats. There was a significant main effect of METH (two-way ANOVA with repeated measures, $\left.F_{(1,69)}=121.066, p<0.001\right)$, time $\left(F_{(6,69)}=\right.$ $42.587 ; p<0.001)$, and a significant interaction between METH and time $\left(F_{(6,69)}=26.453\right.$; $p<0.001) . n=5$ rats per group.

measured by HPLC with electrochemical detection. Samples $(20 \mu \mathrm{l})$ were injected onto a $3 \mu \mathrm{m}$ C18 reverse-phase column $(100 \times 2.0 \mathrm{~mm}$; Phenomenex). Dopamine was eluted using a mobile phase consisting of (in mu) 32 citric acid, 54.3 sodium acetate, 0.074 EDTA, 0.215 octyl sodium sulfate, and $3 \%$ methanol, $\mathrm{pH} 3.8$. Separation of dopamine and DOPAC (3,4-dihydroxyphenylacetic acid) was confirmed before each dialysis experiment. Dopamine was detected with an LC-4B amperometric detector (BAS Bioanalytical Systems, West Lafayette, IN) with a glassy carbon working electrode maintained at a potential of $+0.670 \mathrm{~V}$ relative to an $\mathrm{Ag} / \mathrm{AgCl}$ reference electrode. Data were recorded using the EZ Chrom (Scientific Software, Pleasanton, CA) software package.

\section{Histology}

All dialysis probe placements in the substantia nigra and striatum were verified from $400 \mu \mathrm{M}$ coronal sections. Only data from experiments with verified probe placements were included in the data analysis.

\section{Data analysis}

Striatal VGLUT1 and GAPDH immunoreactivity at $12 \mathrm{~h}$ after METH was analyzed using two-way ANOVA followed by Tukey's post hoc test to determine significant differences between treatment groups. Differences in striatal VGLUT1 and GAPDH immunoreactivity at $24 \mathrm{~h}$ between METH and saline treatments were analyzed by a Student's $t$ test. Striatal VGLUT1 and GAPDH immunoreactivity was analyzed as percentage saline controls. Cortical VGLUT1 mRNA data were analyzed using twoway ANOVA followed by Tukey's post hoc test to determine significant differences between treatment groups. Relative mRNA levels in the cortex were analyzed as VGLUT1 mRNA normalized to cyclophilin mRNA. The vesicular GLU uptake data were analyzed using two-way ANOVA to determine significant differences between treatment groups. In all cases, a level of $p<0.05$ was considered statistically significant.

\section{Results}

In vivo microdialysis experiments were performed to investigate the effects of METH on basal extracellular concentrations of GLU in the lateral striatum. METH produced a gradual and significant increase in extracellular GLU concentrations (Fig. 1). The basal concentration of GLU in dialysate from the striatum before saline treatment was $2029 \pm 227$ and before METH treatment rats was $2061 \pm 229 \mathrm{pg} / 20 \mu \mathrm{l}$. Striatal GLU reached a maximum concentration at $12 \mathrm{~h}(14,224 \pm 1683 \mathrm{pg} / 20 \mu \mathrm{l})$ and remained elevated for at least $24 \mathrm{~h}$ after the last METH injection. No significant increases in extracellular concentrations of GLU were observed in 
A.

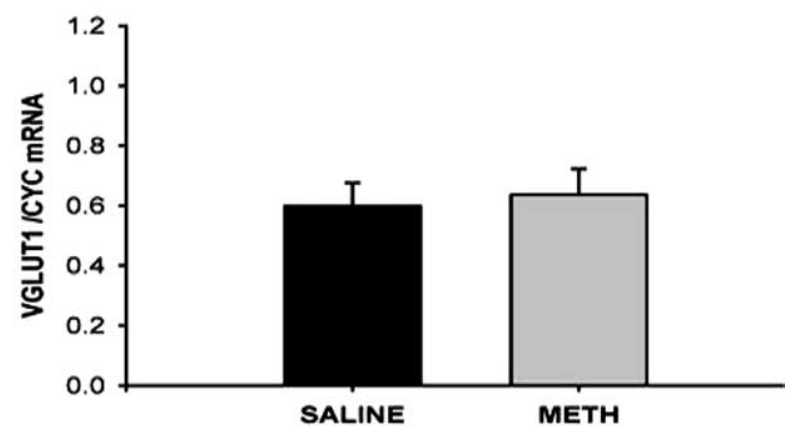

B.

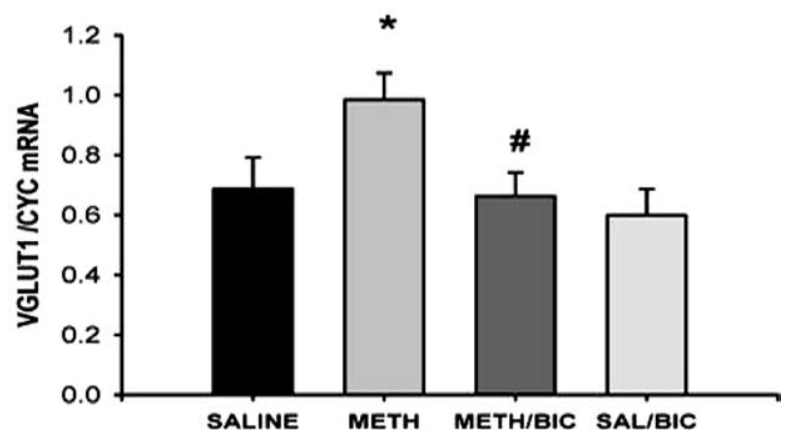

Figure 2. The effect of METH on VGLUT1 mRNA expression in the motor cortex. Four injections of METH (10 mg/kg) or saline $(S A L ; 1 \mathrm{ml} / \mathrm{kg}$ ) were given, one injection every $2 \mathrm{~h} . A$, $B$, Rats were killed at $6 \mathrm{~h}(\boldsymbol{A})$ and $12 \mathrm{~h}(\boldsymbol{B})$ after the last drug administration. Data are expressed as mean VGLUT1/cyclophilin (CYC) \pm SEM. $A$, METH did not change VGLUT1 gene expression $6 \mathrm{~h}$ after the last drug administration. $\boldsymbol{B}$, METH significantly increased $(p<0.05)$ VGLUT1 mRNA expression in the cortex $12 \mathrm{~h}$ after the last METH administration. BIC was reverse dialyzed into the $\mathrm{SN}$ and continuously perfused during the systemic administration of either METH or saline injections. There was a significant main effect of $\mathrm{BIC}\left(F_{(1,28)}=7.647 ; p<0.05\right)$ and a significant interaction between saline- and METH-administered vehicle (VEH) or BIC $\left(F_{(1,28)}=6.185\right.$; $p<0.05) .{ }^{*}$, Significant difference in VGLUT1 mRNA levels between METH plus VEH and saline plus VEH. " , Significant difference between METH plus VEH and METH plus BIC. $n=9$ rats per group.

the saline-treated controls. In contrast to the prolonged effects of METH on GLU release, extracellular DA concentrations in the striatum at $12 \mathrm{~h}$ after the last METH injection did not differ from those measured in saline-treated rats $(3.3 \pm 0.5$ and $2.5 \pm 0.3$ $\mathrm{pg} / 20 \mu \mathrm{l}$ for METH and saline, respectively ( $n=5$ per group).

The main glutamatergic innervation of the striatum arises primarily from the cortex (Gerfen, 1989; Bellomo et al., 1998). Previous findings demonstrated that METH-induced increases in corticostriatal GLU occur via an indirect polysynaptic mechanism that is mediated by $\mathrm{D}_{1}$ DA receptors in the substantia nigra (Mark et al., 2004). However, as shown in Figure 1, extracellular concentrations of GLU remain elevated at $24 \mathrm{~h}$ after METH, a time point at which METH-induced DA release is no longer present to continuously stimulate this polysynaptic pathway and maintain elevated levels of striatal GLU. Therefore, the next series of experiments determined whether a change in the expression of VGLUT1 might underlie the sustained METH-induced increases in corticostriatal GLU release. In corticostriatal glutamatergic neurons, VGLUT1 mRNA is expressed in the cell bodies arising from cortical pyramidal neurons (Ni et al., 1994, 1995). Therefore, the effect of METH on cortical VGLUT1 mRNAs using real-time RT-PCR (Fig. 2) was evaluated. VGLUT1 mRNA levels in the parietal/somatosensory cortex were monitored at $6 \mathrm{~h}(A)$ and $12 \mathrm{~h}(B)$ after the last METH administration. Although VGLUT1 mRNA levels were not affected by METH at $6 \mathrm{~h}$ after the last injection, METH significantly increased the levels of VGLUT1 mRNA ( $53 \pm 8.5 \%)$ in the cortex of rats killed $12 \mathrm{~h}$ after the last injection compared with saline-treated controls. Because the substantia nigra pars reticulata is a major convergence point for the GABAergic outflow of the basal ganglia and regulates the cortex via the thalamus (Deniau and Chevalier, 1985), experiments were performed to determine the effect of intranigral perfusion of BIC, the specific antagonist of the type A GABA receptor, on METH-induced increases in cortical VGLUT1 mRNA levels. BIC significantly attenuated the METH-induced increases in VGLUT1 mRNA in the ipsilateral cortex at $12 \mathrm{~h}$ (Fig. 2B), whereas intranigral perfusion of BIC alone did not affect basal levels of VGLUT1 mRNA in the cortex.

The relative distribution of VGLUT1 protein in subcellular fractions from saline control rats was examined. The optical densities of VGLUT1 per microgram of protein loaded onto the gels for each of the fractions revealed that the vesicle fraction contained the least dense VGLUT1 immunoreactivity (32\% of the membrane and synaptosomal fractions). Similarly, the vesicle protein synaptotagmin was the least dense in the vesicle fraction (28\% of the membrane and synaptosomal fractions). When VGLUT1 immunoreactivity in undrugged or saline controls was examined relative to the vesicle protein synaptotagmin, the ratios did not differ between fractions (mean \pm SEM: synaptosomal, $3.59 \pm 0.19$; membrane-bound, $3.57 \pm 0.11$; crude vesicle, $3.64 \pm 0.06)$.

To determine whether METH increased VGLUT1 protein, we investigated the effect of METH on VGLUT1 immunoreactivity in striatal subcellular fractions $12 \mathrm{~h}$ after the last METH administration. Figure 3 illustrates the effect of METH on VGLUT1 immunoreactivity in the synaptosomal $(A)$, membrane-bound $(B)$, and crude vesicle fraction $(C) 12 \mathrm{~h}$ after the last METH administration. In the synaptosomal fraction, METH significantly increased VGLUT1 protein levels by $32 \pm 5.7 \%$ compared with saline-treated controls. Local perfusion of BIC into the SN significantly attenuated the $\mathrm{METH}$-induced increases in VGLUT1 protein levels in the synaptosomal fraction of the ipsilateral striatum (Fig. 3A). In contrast, METH had no effect on VGLUT1 protein levels in the membrane-bound fraction (Fig. $3 B$ ). In the crude vesicle fraction, METH significantly increased VGLUT1 protein levels by $21 \pm 6.2 \%$ compared with salinetreated controls. Intranigral perfusion of BIC significantly attenuated the METH-induced increases in VGLUT1 protein levels in the crude vesicle fraction in the ipsilateral striatum (Fig. 3C). Similar to the mRNA levels, intranigral perfusion of BIC alone did not significantly affect basal VGLUT1 protein levels in any of subcellular fractions.

Because extracellular concentrations of striatal GLU remained elevated for at least $24 \mathrm{~h}$ after METH, experiments were designed to examine the effect of METH on VGLUT1 immunoreactivity at $24 \mathrm{~h}$ (Fig. 4). Unlike the effects observed $12 \mathrm{~h}$ after drug treatment, only VGLUT1 immunoreactivity in the crude vesicle fraction was significantly increased by $22 \pm 5.3 \%$ at $24 \mathrm{~h}$ after the last METH administration (Fig. 4C). METH did not significantly increase VGLUT1 protein levels in the synaptosomal (Fig. $4 A$ ) or the membrane-bound fraction (Fig. $4 B$ ) $24 \mathrm{~h}$ after the last METH administration. VGLUT1 immunoreactivity in the crude vesicle fraction was also measured at 3 and $7 \mathrm{~d}$ after the last METH administration. METH-induced increases in VGLUT1 protein 
A.

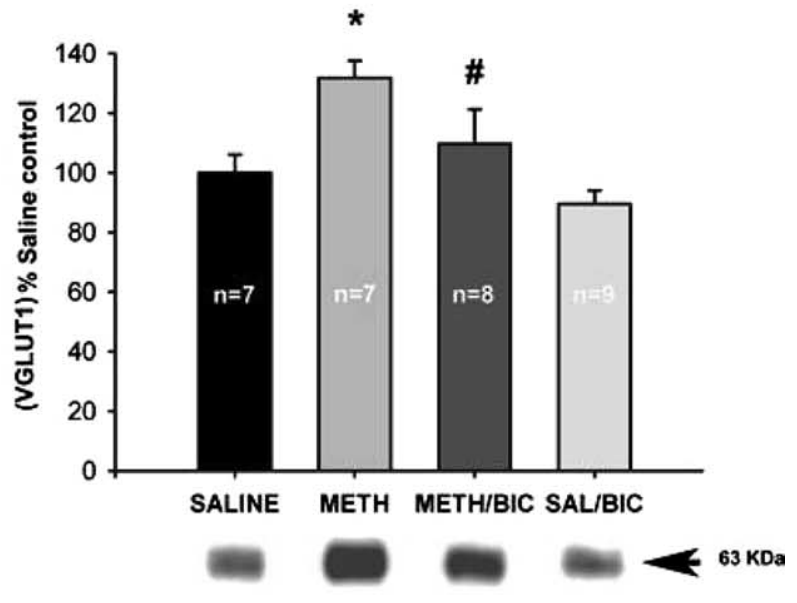

B.

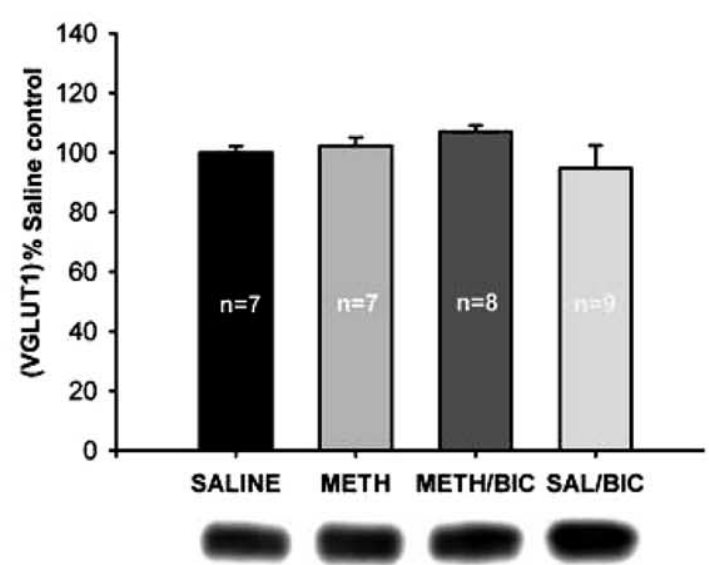

C.

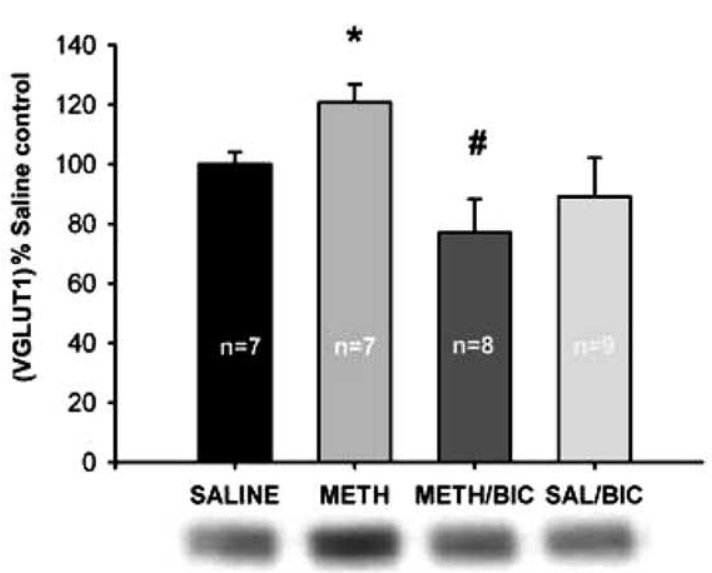

Figure 3. The effect of METH on VGLUT1 immunoreactivity in striatal subcellular fractions $12 \mathrm{~h}$ after the last METH administration. Four injections of METH (10 mg/kg) or saline (SAL; 1 $\mathrm{ml} / \mathrm{kg}$ ) were administered, one injection every $2 \mathrm{~h}$. Rats were killed at $12 \mathrm{~h}$ after the last METH administration. VGLUT1 immunoreactivity is expressed as mean \pm SEM percentage saline control. $A$, In the synaptosomal fraction, METH significantly increased VGLUT1 immunoreactivity $(p<0.05)$ compared with saline-treated rats. BIC was reverse dialyzed into the SN and continuously perfused during the systemic administration of either METH or saline injections. There was a significant main effect of $\mathrm{BIC}\left(F_{(1,27)}=6.929 ; p<0.05\right)$ and a significant interaction between saline- and METH-administered vehicle (VEH) or BIC $\left(F_{(1,27)}=6.117 ; p<0.05\right)$ in the synaptosomal fraction. $\boldsymbol{B}$, Membrane-bound fraction; METH did not have an effect on VGLUT1 immunoreactivity. C, Crude vesicle fraction; METH significantly increased VGLUT1 immunore- levels returned to basal levels by $3 \mathrm{~d}$ after METH administration (data not shown).

As a measure of vesicle protein, synaptotagmin immunoreactivity did not change after METH relative to saline controls in any of the fractions at 12 or $24 \mathrm{~h}$ after drug injection (synaptosomal, $99 \pm 4 \%$; membrane, $78 \pm 9 \%$; crude vesicle, $98 \pm 5 \%$ at $12 \mathrm{~h}$; synaptosomal, $96 \pm 3 \%$; membrane, $99 \pm 4 \%$; crude vesicle, $109 \pm 11 \%$ at $24 \mathrm{~h})$.

The vesicle-associated glycolytic protein GAPDH converts ADP to ATP to support vesicular GLU uptake (Ikemoto et al., 2003). METH-induced changes in GAPDH immunoreactivity at $12 \mathrm{~h}$ were determined from the synaptosomal (Fig. 5A), membrane (Fig. 5B), and crude vesicle (Fig. 5C) fractions of METH and saline-treated rats. METH significantly increased GAPDH protein levels by $21 \pm 4.9 \%$ in the crude vesicle fractions. In contrast, GAPDH immunoreactivity was decreased by $20 \pm 4.9 \%$ in the membrane fractions of METH-treated rats. No effect was observed in the synaptosomal fraction. Intranigral perfusion of BIC significantly attenuated the METH-induced increases in GAPDH protein levels in the crude vesicle fraction, whereas BIC alone had no effect.

The effect of METH on striatal GAPDH immunoreactivity was also examined $24 \mathrm{~h}$ after the last METH administration. METH did not produce significant changes in GAPDH immunoreactivity in either synaptosomal, membrane-bound, or crude vesicle fractions.

An additional glutamatergic innervation of the striatum arises from the thalamus, which predominantly expresses VGLUT2 (Kaneko et al., 2002). Therefore, the effect of METH on striatal VGLUT2 immunoreactivity was examined. Repeated administration of METH did not change VGLUT2 immunoreactivity at $12 \mathrm{~h}$ in any of the striatal subcellular fractions (synaptosomalMETH, $89.7 \pm 26.9 \%$ of saline controls; membrane-boundMETH, $89.8 \pm 26.8 \%$ of saline controls; crude vesicle-METH, $98.1 \pm 28.4 \%$ of saline controls; $n=4-9$ per group).

To directly monitor VGLUT function, we developed a novel application of the microdialysis technique that permitted repeated in vitro measurements of GLU uptake in isolated striatal synaptic vesicles harvested from rats killed $12 \mathrm{~h}$ after the last METH or saline administration. The addition of varied GLU concentrations $(50,100,500,1000$, and $2000 \mu \mathrm{M})$ to the incubation medium containing the isolated vesicles resulted in a concentration-dependent increase in the initial rate of GLU uptake into synaptic vesicles (Fig. 6). $V_{\max }$ and $K_{\mathrm{m}}$ values were determined by double-reciprocal plot. Vesicles from METHtreated rats exhibited an approximately twofold greater maximal rate of GLU uptake ( $V_{\max }$ ) than saline-treated animals ( $V_{\max }$ values: METH, $28.8 \pm 7$ and SALINE, $15.8 \pm 6.4 \mathrm{nmol} / \mathrm{min} / \mathrm{mg}$ protein). The observed $K_{\mathrm{m}}$ values did not differ between METHtreated and saline-treated rats $\left(K_{\mathrm{m}}\right.$ values: METH, $1.3 \pm 0.3$ and SALINE, $1.1 \pm 0.2 \mathrm{~mm}$ ). The values for the $V_{\max }$ and $K_{\mathrm{m}}$ of GLU uptake by vesicles from saline-treated rats are similar to those reported previously (Naito and Ueda, 1985). Values for GLU uptake in the presence of $2 \mathrm{~mm} \mathrm{ATP} \mathrm{at} 30^{\circ} \mathrm{C}$ was linear up to 1.5

\section{$\leftarrow$}

activity $(p<0.05)$ compared with saline-treated rats. There was a significant main effect of $\operatorname{BIC}\left(F_{(1,30)}=10.972 ; p<0.05\right)$ and a significant interaction between saline- and METHadministered VEH or BIC $\left(F_{(1,30)}=4.353 ; p<0.05\right)$ in the crude vesicle fraction. * , Significant difference in VGLUT1 immunoreactivity between METH plus VEH and saline plus VEH. ${ }^{\text {, Signif- }}$ icant difference between METH plus VEH and METH plus BIC. Representative blots are included below the graph. The bands shown represent the $63 \mathrm{kDa}$ VGLUT1 band. Bands are taken from the same blot. 
A.

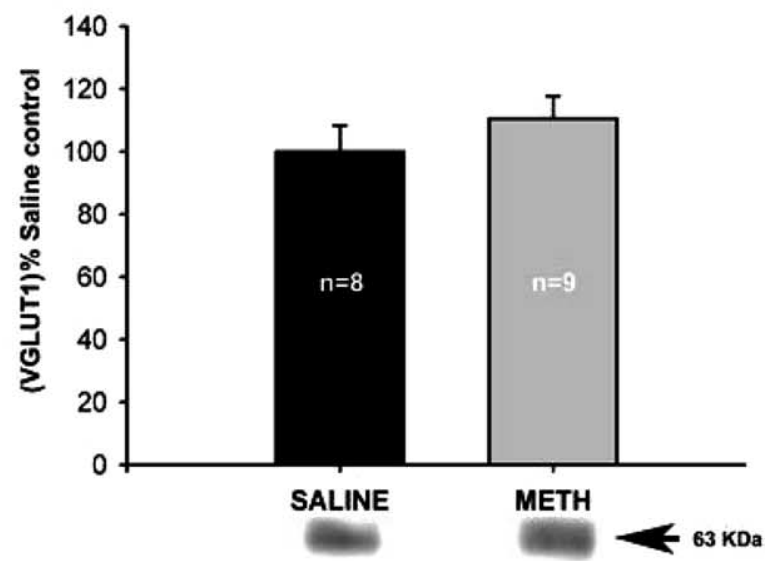

B.

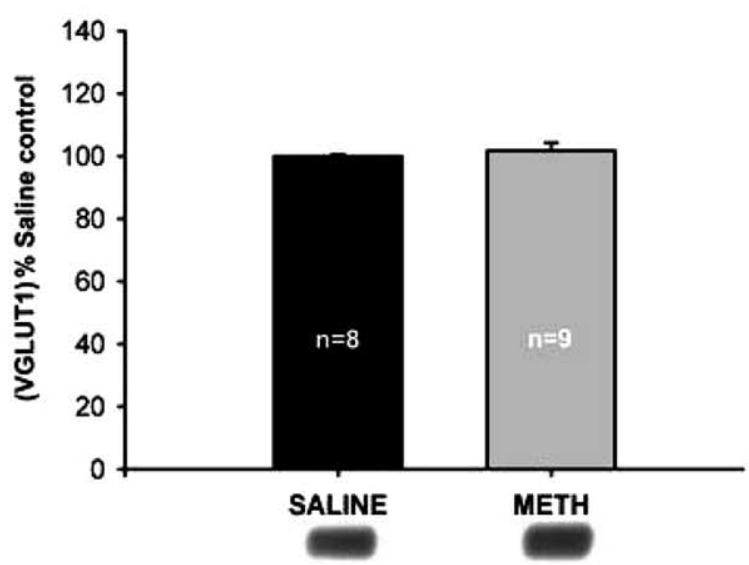

C.

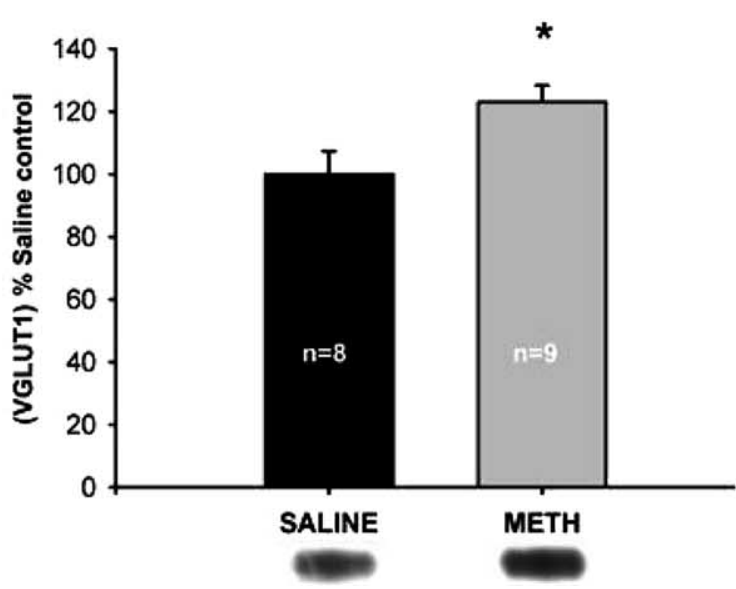

Figure 4. The effect of METH on VGLUT1 immunoreactivity in striatal subcellular fractions at $24 \mathrm{~h}$ after the last METH administration. Four injections of METH $(10 \mathrm{mg} / \mathrm{kg})$ or saline $(1 \mathrm{ml} / \mathrm{kg})$ were given, one injection every $2 \mathrm{~h}$. Rats were killed at $24 \mathrm{~h}$ after the last drug administration. VGLUT1 immunoreactivity is expressed as mean \pm SEM percentage saline control. $\boldsymbol{A}, \boldsymbol{B}, \mathrm{METH}$ did not significantly change VGLUT1 immunoreactivity in either synaptosomal $(A)$ or membrane-bound $(\boldsymbol{B})$ fractions. $\boldsymbol{C}$, METH significantly increased VGLUT1 immunoreactivity $(p<0.05)$ compared with saline-treated rats in the crude vesicle fraction. *, Significant difference in VGLUT1 immunoreactivity between METH and saline. Representative blots are included below the graph. The bands shown represent the $63 \mathrm{kDa}$ VGLUT1 band. Bands are taken from the same blot.
A.

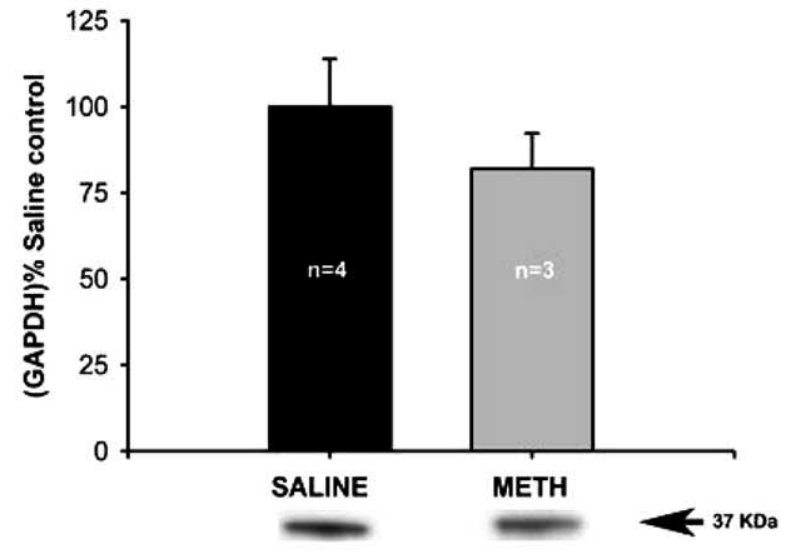

B.

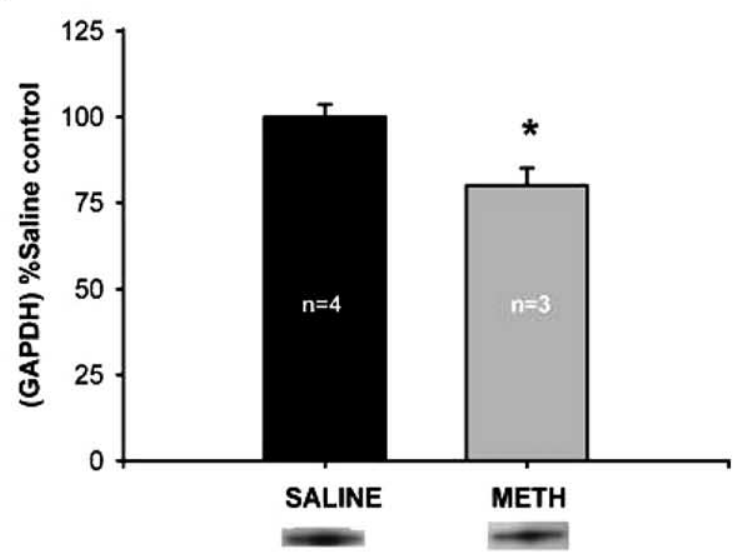

C.

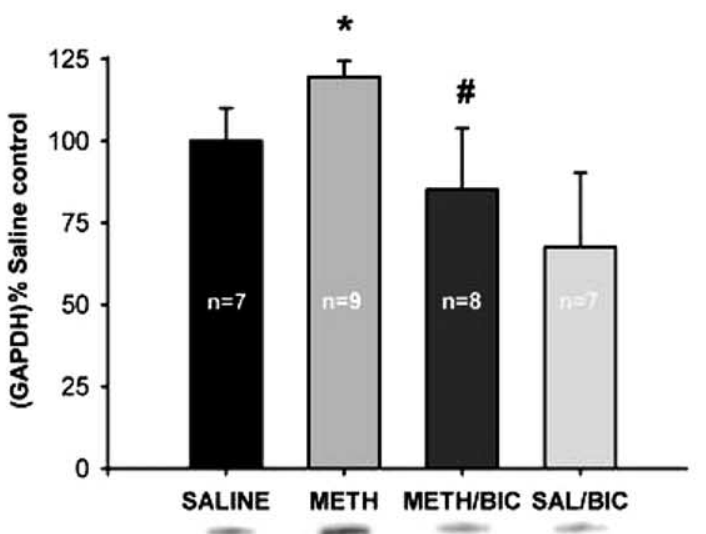

Figure 5. The effect of METH on striatal GAPDH immunoreactivity $12 \mathrm{~h}$ after the last METH administration. Four injections of METH $(10 \mathrm{mg} / \mathrm{kg}$ ) or saline $(1 \mathrm{ml} / \mathrm{kg})$ were administered, one injection every $2 \mathrm{~h}$. Rats were killed at $12 \mathrm{~h}$ after the last drug administration. GAPDH immunoreactivity is expressed as mean \pm SEM percentage saline control. $A$, METH did not significantly change GAPDH immunoreactivity in the synaptosomal fractions. $\boldsymbol{B}$, METH produced a significant decrease in GAPDH immunoreactivity in the membrane fraction $(p<0.05)$ compared with saline-treated rats. C, METH significantly increased ( $p<0.05$ ) GAPDH immunoreactivity in the crude vesicle fraction compared with saline (SAL)-treated rats. BIC was reverse dialyzed into the $\mathrm{SN}$ and continuously perfused during the systemic administration of either METH or saline injections. There was a significant main effect of $\operatorname{BIC}\left(F_{(1,22)}=21.919 ; p<0.05\right)$ and a significant interaction between saline- and METH-administered vehicle (VEH) or BIC $\left(F_{(1,22)}=6.483\right.$; $p<0.05)$ in the crude vesicle fraction. ${ }^{*}$, Significant difference in GAPDH immunoreactivity between METH plus (VEH) and saline plus VEH. " , Significant difference between METH plus VEH and METH plus BIC. Representative blots are included below the graph. The bands shown represent the $37 \mathrm{kDa}$ GAPDH band. Bands are taken from the same blot. 


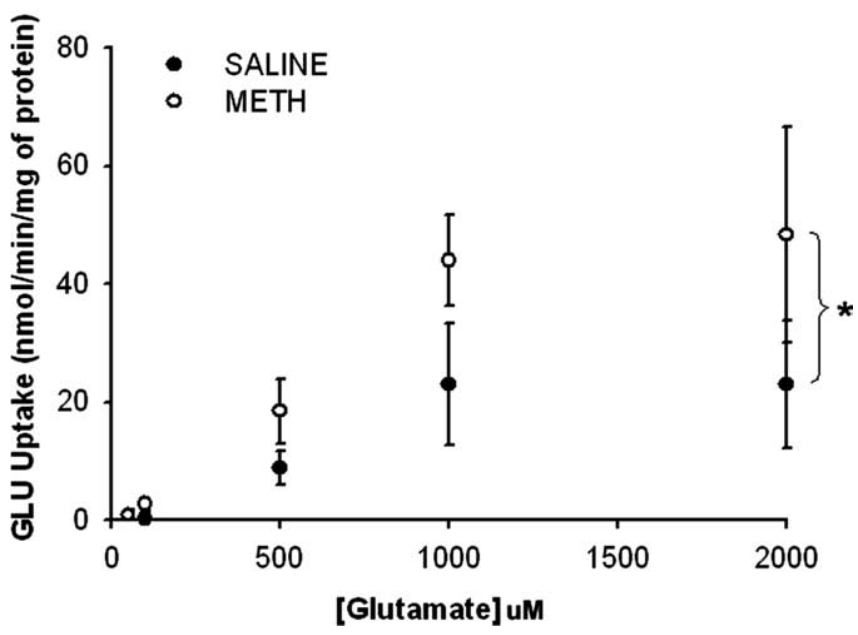

Figure 6. The effect of METH on glutamate uptake into isolated striatal synaptic vesicles. Four injections of METH $(10 \mathrm{mg} / \mathrm{kg})$ or saline $(1 \mathrm{ml} / \mathrm{kg})$ were given, one injection every $2 \mathrm{~h}$. Rats were killed at $12 \mathrm{~h}$ after the last drug administration. Synaptic vesicles from METH- $(\bigcirc)$ and saline-treated (O) rats were incubated with various concentrations of GLU $(50-2000 \mu \mathrm{M})$ for $10 \mathrm{~min}$ at $30^{\circ} \mathrm{C}$. Data are expressed as mean $\pm \mathrm{SEM}$ nanomoles per minutes per milligram of protein. There was a significant main effect of concentration $\left(F_{(4,119)}=8.474 ; p<0.001\right)$ and treatment $\left(F_{(1,119)}=5.284 ; p<0.05\right) . n=9-15$ rats per time point in each group. ${ }^{*}$, Overall significant group difference in vesicular GLU uptake between METH- and saline-treated rats across the glutamate concentrations examined.

min and reached an asymptote by $5 \mathrm{~min}$ (data not shown). There was no significant uptake of GLU by the vesicles in the absence of ATP (data not shown).

\section{Discussion}

The results demonstrate that VGLUT1 expression and function are dynamically regulated by METH through a polysynaptic pathway. The time course of this regulation parallels the protracted increases in extracellular glutamate within the striatum. Although excessive GLU release contributes to the neurotoxic effects of METH (Nash and Yamamoto, 1992; Abekawa et al., 1994), the specific mechanisms underlying the enhanced and sustained elevations in extracellular glutamate were unknown. The current findings illustrate that METH increases the vesicular sequestration of glutamate through the increased expression of VGLUT1 mRNA in the cortex and VGLUT1 protein in the striatum that in turn could mediate the enduring elevations of glutamate after METH.

The early increase in corticostriatal GLU release after METH arises from the stimulation of the $\mathrm{D}_{1} \mathrm{DA}$-associated striatonigral pathway that increases GABA release in the $\mathrm{SNr}$, inhibits nigrothalamic GABAergic outflow via activation of $\mathrm{GABA}_{\mathrm{A}}$ receptors, disinhibits thalamocortical afferents, and subsequently increases corticostriatal GLU release (Mark et al., 2004). In the current report, METH-induced increases in extracellular GLU concentrations in the striatum remain elevated for at least $24 \mathrm{~h}$ after the last injection (Fig. 1); however, augmented increases in extracellular DA produced by METH have returned to basal levels and are no longer present at these late time points (see Results) to stimulate and sustain the polysynaptic pathway. Therefore, an alternative mechanism must be considered that could sustain the elevation of corticostriatal glutamatergic neurotransmission after METH. In this regard, VGLUT1 represents the best marker for corticostriatal glutamatergic neurons (Kaneko and Fujiyama, 2002). VGLUT1 mRNA is expressed in the cell bodies of corticostriatal glutamatergic projections arising from cortical pyramidal neurons (Ni et al., 1994, 1995). Figure 2 illustrates that METH increases VGLUT1 mRNA expression in the cortex at $12 \mathrm{~h}$ after the last METH injection. In addition, local perfusion of a $\mathrm{GABA}_{\mathrm{A}}$ receptor antagonist, $\mathrm{BIC}$, into the substantia nigra blocks the METH-induced increases in cortical VGLUT1 mRNA expression (Fig. $2 \mathrm{~B}$ ). Although the transcriptional mechanisms involved in the gene regulation of cortical VGLUT1 in response to METH have not been established, a METH-induced disinhibition of thalamocortical neurons could stimulate glutamate receptors in the cortex (Monaghan and Cotman, 1985) and initiate a cascade of signal transduction events that increase VGLUT1 transcription. Future studies that determine the underlying transcriptional events mediating the VGLUT1 sensitivity to METH exposure are warranted.

Increases in cortical VGLUT1 mRNA levels may reflect enhanced activity of corticostriatal glutamatergic neurons at $12 \mathrm{~h}$ after the last METH administration. In fact, targeted deletion of the VGLUT1 gene in mice drastically reduces glutamatergic neurotransmission, whereas overexpression of VGLUT1 leads to increased glutamatergic neurotransmission (Wojcik et al., 2004). In addition, our finding that the local infusion of BIC into the SN blocks the METH-induced increases in cortical VGLUT1 mRNA expression explains how $\mathrm{GABA}_{\mathrm{A}}$ antagonism blocks the METHinduced increase in corticostriatal GLU release (Mark et al., 2004). Therefore, these data suggest that cortical VGLUT1 mRNA transcription can be regulated from a midbrain region extrinsic to the cortex and may play a role in sustaining elevated extracellular GLU concentrations after METH.

Because increases in VGLUT1 mRNA in cortex may not translate into enhanced VGLUT1 protein levels, a separate series of experiments were conducted to measure VGLUT1 protein immunoreactivity. There is long-standing evidence that proteins are initially translated in the cell bodies and then subsequently transported along axonal microtubules to the nerve terminal (Vallee and Bloom, 1991). In the current study, VGLUT1 protein is increased in striatal subcellular fractions at $12 \mathrm{~h}$ (Fig. 3) and $24 \mathrm{~h}$ (Fig. 4) after METH administration. Therefore, the relatively rapid increase in striatal VGLUT1 resulting from protein translation in the cortical cell bodies and transport to striatal nerve terminals appears inconsistent with protein transport from the soma that would typically require several days to reach the nerve terminals (Campenot and Eng, 2000). Therefore, the increases in cortical VGLUT1 mRNA and striatal VGLUT1 protein that occur within a similar time frame raise the possibility that METH may increase VGLUT1 protein synthesis locally in the striatum rather than in cortical cell bodies (Campenot and Eng, 2000). In fact, there is evidence that axons contain specific mRNAs and ribosomes for the synthesis of proteins, thus circumventing timeconsuming transport from cell bodies to nerve terminals (Alvarez and Benech, 1983).

The most consistent increases in VGLUT1 occurred in the crude vesicle fraction, although the exact location of these changes cannot be defined. It could be assumed that the vesicle fraction would contain the densest VGLUT and synaptotagmin immunoreactivities if it indeed was a purified vesicle fraction. However, the vesicle fraction had the least dense VGLUT1 and synaptotagmin immunoreactivities of all fractions. This could be because of the inclusion, centrifugation, and attachment of free vesicles into the membrane-associated fraction during the differential centrifugation process. In addition, the inclusion of nonvesicle proteins such as endoplasmic reticulum and Golgi could have contributed to the overall measured protein content of the crude vesicle fraction. Regardless, the changes in VGLUT1 may 
reflect an increase in the density of VGLUTs per vesicle rather than an increase in the absolute number of vesicles because the vesicle protein synaptotagmin did not change after METH. In addition, the results suggest that relatively modest increases in VGLUT1 can have marked effects on increasing and sustaining extracellular GLU concentrations in the striatum; however, the exact quantitative relationship between the magnitude of change in VGLUT1 expression and the overall amount of GLU released per vesicle is unknown. Unfortunately, it is not feasible to measure extracellular GLU simultaneous with pharmacological inhibition of VGLUT because all known VGLUT antagonists are essential dyes that can preclude the electrochemical or fluorescent detection of glutamate.

METH-induced increases in VGLUT1 protein concentrations in the crude vesicle fraction (Fig. $3 C$ ) coincide with an increased maximal rate of GLU uptake ( $V_{\max }$ ) into synaptic vesicles (Fig. 6). These observations are consistent with previous reports that VGLUT1-associated synaptic vesicles have the capacity to sequester larger quantities of GLU for subsequent release (Wilson et al., 2005). Moreover, it has been reported that the absolute number of vesicular transporters also greatly influences both the extent of vesicle loading and the eventual enhanced efficiency of vesiclemediated GLU neurotransmission (Wilson et al., 2005). Thus, METH-induced increases in VGLUT1 in the crude vesicle fraction facilitate the increased accumulation of GLU into synaptic vesicles and ultimately contribute to the enhanced and sustained levels of extracellular GLU in the striatum after METH.

GAPDH is a glycolytic enzyme that plays an essential role in GLU uptake and GLU neurotransmission as evidenced by the findings that GAPDH inhibition significantly reduces the accumulation of GLU into synaptic vesicles (Ikemoto et al., 2003). Our finding that GAPDH levels are decreased in the membrane fraction and increased in the crude vesicle fraction at $12 \mathrm{~h}$ may reflect a redistribution of this protein or its associated vesicle to the intracellular pool for vesicular uptake of glutamate from the cytosol. Regardless, increases in GAPDH protein in the crude vesicle fraction may provide the needed energy to support GLU uptake into vesicles and sustain levels of extracellular GLU in the striatum after METH. The stimulus for the increase in GAPDH remains unknown, but it may derive from the increase in glucose metabolism produced by METH (Pontieri et al., 1990).

In contrast to VGLUT1, VGLUT2 immunoreactivity was unaltered after METH. VGLUT2 is associated predominantly with thalamostriatal projections, whereas VGLUT1 is associated with corticostriatal neurons (Kaneko and Fujiyama, 2002; Bacci et al., 2004). Mark et al. (2004) reported that METH acutely decreases nigrothalamic GABAergic activity to subsequently enhance corticostriatal GLU release, presumably through the disinhibition of thalamocortical afferents. Based on this circuitry, it is interesting that METH does not alter VGLUT2 immunoreactivity in the striatum because decreases in GABAergic activity to the thalamus should increase the activity of thalamostriatal glutamatergic efferents. Although other innervations of the thalamus could modulate thalamostriatal glutamatergic activity, such as GABAergic efferents from the globus pallidus (Smith et al., 2004) and cholinergic inputs from the pedunculopontine tegmental nucleus (Hallanger et al., 1987), little is known about the effects of METH on these systems. In contrast, the stimulatory effects of METH on corticostriatal glutamatergic activity were described previously (Nash and Yamamoto, 1992). Moreover, cortical ablation attenuates METH-induced increases in striatal GLU release and the long-term damage to striatal dopamine terminals (Burrows and Yamamoto, 2003). The finding that striatal VGLUT2 protein lev- els are unaltered after METH highlights the novel finding of a differential responsiveness to METH in subpopulations of glutamatergic thalamic neurons (i.e., thalamocortical) that could selectively affect the cortex to mediate the sensorimotor and psychostimulant effects of METH.

In conclusion, direct evidence is presented illustrating that striatal VGLUT1 function and expression is regulated by a polysynaptic pathway and contributes to the plastic and potentially pathological changes in corticostriatal glutamatergic terminals produced by METH. Moreover, because excessive release of GLU plays a pivotal role in multiple disease states, an understanding of the regulation of VGLUT1 expression and function may reveal new targets for therapeutic intervention of neurodegenerative disease.

\section{References}

Abekawa T, Ohmori T, Koyama T (1994) Effects of repeated administration of a high dose of methamphetamine on dopamine and glutamate release in rat striatum and nucleus accumbens. Brain Res 643:276-281.

Alvarez J, Benech CR (1983) Axoplasmic incorporation of amino acids in a myelinated fiber exceeds that of its soma: a radioautographic study. Exp Neurol 82:25-42.

Bacci JJ, Kachidian P, Kerkerian-Le Goff L, Salin P (2004) Intralaminar thalamic nuclei lesions: widespread impact on dopamine denervationmediated cellular defects in the rat basal ganglia. J Neuropathol Exp Neurol 63:20-31.

Bellocchio EE, Reimer RJ, Fremeau Jr RT, Edwards RH (2000) Uptake of glutamate into synaptic vesicles by an inorganic phosphate transporter. Science 289:957-960.

Bellomo M, Giuffrida R, Palmeri A, Sapienza S (1998) Excitatory amino acids as neurotransmitters of corticostriatal projections: immunocytochemical evidence in the rat. Arch Ital Biol 136:215-223.

Burrows KB, Yamamoto BK (2003) Methamphetamine toxicity: roles for glutamate, oxidative processes, and metabolic stress. In: Contemporary clinical neuroscience: glutamate and addiction (Herman BH, ed), pp 211226. Totowa, NJ: Humana.

Campenot RB, Eng H (2000) Protein synthesis in axons and its possible functions. J Neurocytol 29:793-798.

Deniau JM, Chevalier G (1985) Disinhibition as a basic process in the expression of striatal functions. II. The striato-nigral influence on thalamocortical cells of the ventromedial thalamic nucleus. Brain Res 334:227-233.

Donzanti BA, Yamamoto BK (1988) An improved and rapid HPLC-EC method for the isocratic separation of amino acid neurotransmitters from brain tissue and microdialysis perfusates. Life Sci 43:913-922.

Eisch AJ, Schmued LC, Marshall JF (1998) Characterizing cortical neuron injury with Fluoro-Jade labeling after a neurotoxic regimen of methamphetamine. Synapse 30:329-333.

Fykse EM, Iversen EG, Fonnum F (1992) Inhibition of L-glutamate uptake into synaptic vesicles. Neurosci Lett 135:125-128.

Gerfen CR (1989) The neostriatal mosaic: striatal patch-matrix organization is related to cortical lamination. Science 246:385-388.

Hallanger AE, Levey AI, Lee HJ, Rye DB, Wainer BH (1987) The origins of cholinergic and other subcortical afferents to the thalamus in the rat. J Comp Neurol 262:105-124.

Hotchkiss AJ, Gibb JW (1980) Long-term effects of multiple doses of methamphetamine on tryptophan hydroxylase and tyrosine hydroxylase activity in rat brain. J Pharmacol Exp Ther 214:257-262.

Ikemoto A, Bole DG, Ueda T (2003) Glycolysis and glutamate accumulation into synaptic vesicles. Role of glyceraldehyde phosphate dehydrogenase and 3-phosphoglycerate kinase. J Biol Chem 278:5929-5940.

Imam SZ, el Yazal J, Newport GD, Itzhak Y, Cadet JL, Slikker Jr W, Ali SF (2001) Methamphetamine-induced dopaminergic neurotoxicity: role of peroxynitrite and neuroprotective role of antioxidants and peroxynitrite decomposition catalysts. Ann NY Acad Sci 939:366-380.

Kadota T, Kadota K (1973) Isolation of coated vesicles, plain synaptic vesicles, and flocculent material from a crude synaptosome fraction of guinea pig whole brain. J Cell Biol 58:135-151.

Kaneko T, Fujiyama F (2002) Complementary distribution of vesicular glu- 
tamate transporters in the central nervous system. Neurosci Res 42:243-250.

Kaneko T, Fujiyama F, Hioki H (2002) Immunohistochemical localization of candidates for vesicular glutamate transporters in the rat brain. J Comp Neurol 444:39-62.

Lipton SA, Rosenberg PA (1994) Excitatory amino acids as a final common pathway for neurologic disorders. N Engl J Med 330:613-622.

Lovinger DM, Partridge JG, Tang KC (2003) Plastic control of striatal glutamatergic transmission by ensemble actions of several transmitters and targets for drugs of abuse. Ann NY Acad Sci 1003:226-240.

Mark KA, Soghomonian JJ, Yamamoto BK (2004) High-dose methamphetamine acutely activates the striatonigral pathway to increase striatal glutamate and mediate long-term dopamine toxicity. J Neurosci 24:11449-11456.

Matuszewich L, Yamamoto BK (1999) Modulation of GABA release by dopamine in the substantia nigra. Synapse 32:29-36.

Monaghan DT, Cotman CW (1985) Distribution of $N$-methyl-D-aspartatesensitive L- $\left[{ }^{3} \mathrm{H}\right]$ glutamate-binding sites in rat brain. J Neurosci 5:2909-2919.

Naito S, Ueda T (1985) Characterization of glutamate uptake into synaptic vesicles. J Neurochem 44:99-109.

Nash JF, Yamamoto BK (1992) Methamphetamine neurotoxicity and striatal glutamate release: comparison to 3,4-methylenedioxymethamphetamine. Brain Res 581:237-243.

Ni B, Rosteck Jr PR, Nadi NS, Paul SM (1994) Cloning and expression of a cDNA encoding a brain-specific $\mathrm{Na}(+)$-dependent inorganic phosphate cotransporter. Proc Natl Acad Sci USA 91:5607-5611.

Ni B, Wu X, Yan GM, Wang J, Paul SM (1995) Regional expression and cellular localization of the $\mathrm{Na}(+)$-dependent inorganic phosphate cotransporter of rat brain. J Neurosci 15:5789-5799.

O’Dell SJ, Weihmuller FB, Marshall JF (1991) Multiple methamphetamine injections induce marked increases in extracellular striatal dopamine which correlate with subsequent neurotoxicity. Brain Res 564:256-260.

Paxinos G, Watson C (1982) The rat brain stereotaxic coordinates. New York: Academic.

Pontieri FE, Crane AM, Seiden LS, Klevin MS, Perrino LJ (1990) Metabolic mapping of the effects of intravenous methamphetamine administration in freely moving rats. Psychopharmacology (Berl) 102:175-182.

Price DL (1999) New order from neurological disorders. Nature 399:A3-A5.

Ricaurte GA, Guillery RW, Seiden LS, Schuster CR, Moore RY (1982) Do- pamine nerve terminal degeneration produced by high doses of methylamphetamine in the rat brain. Brain Res 235:93-103.

Riddle EL, Topham MK, Haycock JW, Hanson GR, Fleckenstein AE (2002) Differential trafficking of the vesicular monoamine transporter-2 by methamphetamine and cocaine. Eur J Pharmacol 449:71-74.

Smith Y, Raju DV, Pare JF, Sidibe M (2004) The thalamostriatal system: a highly specific network of the basal ganglia circuitry. Trends Neurosci 27:520-527.

Sonsalla PK, Nicklas WJ, Heikkila RE (1989) Role for excitatory amino acids in methamphetamine-induced nigrostriatal dopaminergic toxicity. Science 243:398-400.

Steiger JL, Bandyopadhyay S, Farb DH, Russek SJ (2004) cAMP response element-binding protein, activating transcription factor-4, and upstream stimulatory factor differentially control hippocampal GABABRla and GABABR1b subunit gene expression through alternative promoters J Neurosci 24:6115-6126.

Stephans SE, Yamamoto BK (1994) Methamphetamine-induced neurotoxicity: roles for glutamate and dopamine efflux. Synapse 17:203-209.

Takamori S, Rhee JS, Rosenmund C, Jahn R (2000) Identification of a vesicular glutamate transporter that defines a glutamatergic phenotype in neurons. Nature 407:189-194.

Takamori S, Rhee JS, Rosenmund C, Jahn R (2001) Identification of differentiation-associated brain-specific phosphate transporter as a second vesicular glutamate transporter (VGLUT2). J Neurosci 21:RC182(1-6).

Teng L, Crooks PA, Sonsalla PK, Dwoskin LP (1997) Lobeline and nicotine evoke $[3 \mathrm{H}]$ overflow from rat striatal slices preloaded with $[3 \mathrm{H}]$ dopamine: differential inhibition of synaptosomal and vesicular $[3 \mathrm{H}]$ dopamine uptake. J Pharmacol Exp Ther 280:1432-1444.

Vallee RB, Bloom GS (1991) Mechanisms of fast and slow axonal transport. Annu Rev Neurosci 14:59-92.

Wilson NR, Kang J, Hueske EV, Leung T, Varoqui H, Murnick JG, Erickson JD, Liu G (2005) Presynaptic regulation of quantal size by the vesicular glutamate transporter VGLUT1. J Neurosci 25:6221-6234.

Wojcik SM, Rhee JS, Herzog E, Sigler A, Jahn R, Takamori S, Brose N, Rosenmund C (2004) An essential role for vesicular glutamate transporter 1 (VGLUT1) in postnatal development and control of quantal size. Proc Natl Acad Sci USA 101:7158-7163.

Yamamoto BK, Pehek EA (1990) A neurochemical heterogeneity of the rat striatum as measured by in vivo electrochemistry and microdialysis. Brain Res 506:236-242. 